\title{
O SABER REFLEXIVO-COLABORATIVO NO ENSINO E APRENDIZAGEM DE PORTUGUÊS LÍNGUA ESTRANGEIRA: significados construídos na interação do par mais experiente com o professor em formação
}

\author{
Marina Ayumi Izaki Gómez ${ }^{1}$ \\ Nelson Viana ${ }^{2}$
}

\begin{abstract}
Resumo
Um dos grandes desafios na formação de professores é lidar com o distanciamento entre teoria e prática (LEFFA, 2006). Esse tema tem sido foco de discussão promovida por diversos autores da área de ensino de línguas, o que corrobora a sua relevância investigativa. No que se refere à área de Português Língua Estrangeira (PLE), mesmo com a crescente demanda pela aprendizagem do idioma por estrangeiros, "chama a atenção o fato de haver ainda tão pouca pesquisa na área de formação do professor de PLE" (DUTRA, 2010, p.13). Levando em consideração a escassez de estudos sobre a formação desse profissional, objetivamos neste artigo apresentar e discutir significados construídos na interação do par mais experiente com professores em formação que compuseram parte dos resultados obtidos em pesquisa de doutorado. Os aportes reflexivo e sociocultural fundamentaram o estudo. Criar oportunidades para que o professor em formação possa discutir sua prática e a de seus colegas é imprescindível para desenvolver o processo reflexivo sobre o dizer e o fazer pedagógicos e o par mais experiente como mediador dessa ação pode potencialmente colaborar para construção de percepção crítica. Sob o paradigma qualitativo de base etnográfica e interpretativista foram analisadas interações, envolvendo professores em formação e um par mais experiente, priorizando-se o processo de construção de significados acerca da reflexão sobre a prática. Os professores em formação (graduandos em Letras) ministraram cursos de PLE, vinculados a Projeto de Extensão do Departamento de Letras de uma universidade pública do interior paulista. O par mais experiente é professora e pesquisadora da referida área. Com base nos resultados alcançados, concluímos que a ação de pelo menos um par mais experiente tem potencial para auxiliar os professores de PLE na construção de reflexão de modo colaborativo por meio da interação. Como desdobramentos dessa pesquisa de doutorado, foi proposto um organograma base (incluído neste artigo), de trabalho colaborativo em PLE e do Saber Reflexivo-Colaborativo, na formação de professores.
\end{abstract}

Palavras-chave: Formação de professores, Interação, Reflexão.

\section{REFLECTIVE AND COLLABORATIVE KNOWLEDGE IN THE TEACHING OF PORTUGUESE AS A FOREIGN LANGUAGE: the construction of meanings in the process of interaction between pre-service teachers and a more experienced peer}

\begin{abstract}
One of the challenges in teacher education is dealing with the gap between theory and practice (LEFFA, 2006). This has been the focus of discussions promoted by several authors of the Language Teaching field, which corroborates the relevance of developing research, approaching the topic. Taking into account that teacher education in the field of Portuguese as a foreign language is still under investigated (DUTRA, 2010) and that it should receive more attention, this article aims at presenting and discussing discursive meanings produced in the process of interaction between an expert teacher and pre-service teachers. Based upon findings from a doctoral research, this work relies on reflective processes theories and on the sociocultural approach applied to teacher education. Creating opportunities which allows pre-service teachers to discuss his/her practice is imperative to develop the reflective process. In this sense, the expert teacher can collaborate to expand critical perception. Research methodology relies on an ethnographic qualitative perspective. Based on the

\footnotetext{
${ }^{1}$ Universidade Federal de São Carlos (UFSCAR), São Carlos - SP - Brasil. Doutora em Linguística. ORCID

$<$ https://orcid.org/0000-0001-7762-2500>.E-mail: marinaizaki@gmail.com

${ }^{2}$ Universidade Federal de São Carlos (UFSCAR), São Carlos - SP - Brasil. Docente. Doutor em Estudos

Linguísticos. ORCID <https://orcid.org/0000-0001-9712-6432>. E-mail: nlsviana@ufscar.br
} 
findings achieved, we conclude that the action of at least one expert teacher has the potential to help pre-service teachers of PFL to construct reflection collaboratively through interaction. As a result of the doctoral research, we propose an organizational chart (included in this article), related to collaborative work in PFL and Reflective-Collaborative Knowledge, in teacher education.

Key words: Teacher education, Interaction, Reflection.

\section{EL SABER REFLEXIVO-COLABORATIVO EN LA ENSEÑANZA DE PORTUGUÉS LENGUA EXTRANJERA: construcción de significados en la interacción del profesor tutor y profesores en formación}

\section{Resumen}

Uno de los grandes desafíos en la formación de profesores es el alejamiento entre teoría y práctica (LEFFA, 2006). Ese tema ha sido discutido por diversos autores en el área de enseñanza de lenguas, lo que corrobora su relevancia investigativa. Con respecto al dominio científico del portugués como lengua extranjera (PLE), ante la creciente demanda de aprendizaje del idioma por extranjeros, "llama la atención el hecho de que aún no exista un número considerable de investigaciones en el área de formación de profesores de PLE" (DUTRA, 2010, p.13). Considerando ese contexto, los objetivos de este artículo son presentar y discutir los significados construidos en la interacción entre el profesional de PLE con experiencia/profesor tutor y los profesores en formación. Los datos discutidos son parte de registros obtenidos para una investigación de doctorado. Los aportes reflexivo y sociocultural fundamentaron el estudio. Crear oportunidades para que el profesor en formación pueda discutir su práctica y la de sus colegas es imprescindible para desarrollar el proceso reflexivo sobre el decir y el hacer pedagógicos. En ese proceso, la mediación del profesional de PLE con experiencia puede potencialmente colaborar para la construcción de percepción crítica. Bajo el paradigma cualitativo de base etnográfica e interpretativista se analizaron interacciones, involucrando profesores en formación y un profesional de PLE con experiencia, priorizando el proceso de construcción de significados acerca de la reflexión sobre la práctica. Los profesores en formación (estudiantes de Letras) impartieron cursos de PLE, vinculados a un Proyecto de Extensión de una universidad pública en Brasil. El profesional de PLE con experiencia es profesora e investigadora en la misma área. Con base en los resultados alcanzados, concluimos que la acción de, por lo menos, un profesional con experiencia tiene potencial para auxiliar a los profesores de PLE en formación, para la construcción de reflexión colaborativa a través de la interacción. Como desdoblamientos de esa investigación de doctorado, se propuso un organigrama base (incluido en este artículo), de trabajo colaborativo en PLE y del Saber Reflexivo-Colaborativo, en la formación de profesores.

Palabras clave: Formación de profesores, Interacción, Reflexión.

\section{Introdução}

Um dos grandes desafios na formação de professores, apontado por Leffa (2006), é lidar com o distanciamento que pode ocorrer entre teoria e prática. O dizer e o fazer pedagógicos podem ocupar um "lugar" não harmônico na ação docente, potencializando o complexo processo de ensino e aprendizagem. Dada a relevância desse tema, muitos autores da área promovem discussão sobre a importância do futuro professor ser também pesquisador e desenvolver iniciação científica durante a formação (PAIVA, 1996), bem como sobre a necessária construção de prática reflexiva junto ao aluno-professor para que ele possa 
desenvolver a criticidade e a autonomia (GRANDCOLAS \& VASSEUR, 1999; VIEIRAABRAHÃO, 2001; KANEKO-MARQUES, 2011; ROCHA \& GILENO, 2016; entre outros).

Nessa perspectiva, levando em consideração a escassez de estudos acerca da formação de professores de Português Língua Estrangeira (PLE) (DUTRA, 2010), objetivamos neste artigo apresentar e discutir significados construídos na interação do par mais experiente com professores em formação que compuseram parte de resultados obtidos em pesquisa de doutorado, por nós desenvolvida. Os aportes reflexivo e sociocultural fundamentaram o estudo. As interações foram analisadas sob o paradigma qualitativo de base etnográfica e interpretativista. Os participantes são graduandos em Letras que ministram cursos de PLE e o par mais experiente é professora e pesquisadora da referida área. Como desdobramentos dessa pesquisa de doutorado, incluímos neste artigo um organograma base, de trabalho colaborativo em PLE e do Saber Reflexivo-Colaborativo, na formação de professores.

Este artigo está organizado em quatro partes: fundamentação teórica (discussão sobre abordagens reflexiva e sociocultural), metodologia (descrição do contexto de coleta de dados e do perfil dos participantes), análise dos dados (significados construídos na interação do par mais experiente com os professores em formação) e conclusão.

\section{Fundamentação teórica}

O conhecimento ${ }^{3}$ não é um espelho das coisas ou do mundo externo (...). $O$ conhecimento sob forma de palavra, de ideia, de teoria, é o fruto de uma tradução/reconstrução por meio da linguagem e do pensamento (MORIN, 2005, p. 20). Com base nessa premissa, compreendemos que o conhecimento/saber não existe isoladamente, é (re)construído de modo contínuo na interação por meio da linguagem. O mesmo ocorre com o saber docente, definido como um saber plural, formado pelo amálgama, mais ou menos coerente, de saberes oriundos da formação profissional e de saberes disciplinares, curriculares e experienciais (TARDIF, 2002, p. 36). O saber profissional é concebido como um conjunto de saberes transmitidos pelas instituições de formação de professores (TARDIF, 2002, p. 36); o saber disciplinar está relacionado às disciplinas oferecidas nas instituições, específicas para cada formação; o saber curricular abrange os programas pedagógicos em que constam abordagem, metodologias, entre outros; e o saber experiencial é construído ao longo da experiência como profissional, sem estar relacionado aos ambientes formais de aprendizagem. Como explicitado, o conhecimento que o professor necessita para realizar seu

\footnotetext{
${ }^{3}$ Neste artigo, conhecimento e saber são concebidos como sinônimos.
} 
ofício já é constitutivamente plural, o que implica ressignificação contínua de saberes ao longo do exercício profisssional. Essa ressignificação pode ser mais profícua com a ação colaborativa de um par mais experiente na interação.

Segundo Leffa (2006, p. 175), interação é um contato que produz mudança em cada um dos participantes e [...] pode ocorrer [...] entre pessoas e objetos - mas sempre afetando a ambos. Para que haja mudança, é preciso que a interação provoque reflexão e seja, portanto, significativa. Nesse aspecto, concordamos com Barbirato (2005, p. 30-31) que a concebe como um processo de negociação de significados. É na interação que nos constituímos também como sujeitos. Sob a perspectiva bakhtiniana, somos sujeitos incompletos e buscamos completude em outro indivíduo que, por sua vez, também é incompleto. Esse outro tem, portanto, uma experiência de mim que eu próprio não tenho, mas que posso, por meu turno, ter a respeito dele. Este "acontecimento" nos mostra a nossa incompletude e constitui o Outro como o único lugar possível de uma completude sempre impossível [...] (GERALDI, 2010, p. 107). Com base nessa reflexão, o sujeito está em ininterrupta (re)construção e o outro é considerado parte indispensável nesse processo.

Sob a mesma linha argumentativa, na teoria sociocultural, o homem também constrói significados por meio de ações sociais, sendo o desenvolvimento cognitivo [...] um processo interativo, mediado pela cultura, pelo contexto, pela linguagem e pela interação social (JOHNSON, 2009 apud VIEIRA-ABRAHÃO, 2012, p. 460). Das várias mediações humanas existentes, podemos destacar a participação guiada em que se realiza ação conjunta de um iniciante e um par mais competente no desenvolvimento de uma tarefa (VIEIRA-ABRAHÃO, 2012, p. 462-463). Para Vygotsky (1932), um dos expoentes dessa teoria e cujos trabalhos são referências, o homem por sua origem e natureza, não pode nem existir nem conhecer o desenvolvimento próprio de sua espécie como uma mônada isolada: ele tem, necessariamente, seu prolongamento nos outros; tomado em si, ele não é um ser completo (IVIC, 2010, p.16).

Ao transpormos essa perspectiva para o contexto de formação de professores de línguas e, especificamente, de PLE podemos reconhecer como relevante que a interação seja construída com pelo menos um par mais experiente, atuando como mediador da reflexão produzida. Nesse espaço de interação, a abordagem reflexiva pode potencialmente contribuir para a (re)construção de significados sobre o dizer e o fazer pedagógicos.

Concebemos reflexão/reflexividade como sendo uma auto-análise sobre nossas próprias ações, que pode ser feita comigo mesmo ou com os outros (LIBÂNEO, 2006, p. 55). 
Para Zeichner (2008), o processo de reflexão é uma ação social e, portanto, envolve outros sujeitos.

De acordo com Schön (2000), podemos refletir antes, durante e depois da ação por meio de processos denominados conhecer-na-ação, conhecimento-na-ação, reflexão-na-ação e reflexão-sobre-a ação. O conhecer-na-ação refere-se aos tipos de conhecimento que revelamos em nossas ações inteligentes - performances fisicas, publicamente observáveis, como andar de bicicleta [...] (SCHÖN, 2000, p. 31). Quando tentamos explicar e/ou teorizar esse conhecimento implícito, manifestado nas ações, ele é qualificado por Schön (2000) como conhecimento-na-ação. A reflexão-na-ação envolve um elemento surpresa, o que implica pensar criticamente no presente-da-ação, ou seja, durante a ação para obter significado imediato. A reflexão-sobre-a ação é refletir criticamente sobre a ação passada. Para resumir essas concepções discutidas no trabalho de Schön (2000), inserimos a seguir o quadro elaborado na tese de doutorado de Izaki Gómez (2018, p. 59):

Figura 1. Izaki Gómez (2018, p. 59)

\begin{tabular}{|l|l|}
\hline \multicolumn{2}{|c|}{ Quadro 4 - Reflexão sob perspectiva de Schön (2000) } \\
\hline Conhecer-na-ação & $\begin{array}{l}\text { Conhecimentos revelados espontaneamente } \\
\text { em nossas ações; conhecimento implícito. }\end{array}$ \\
\hline Conhecimento-na-ação & $\begin{array}{l}\text { Tentativa de teorizar, de descrever o } \\
\text { conhecer-na-ação. }\end{array}$ \\
\hline Reflexão-na-ação & $\begin{array}{l}\text { Reflexão ocorre em um presente-da-ação } \\
\text { em que é possível intervir na situação } \\
\text { em desenvolvimento. }\end{array}$ \\
\hline Reflexão-sobre-a ação & Refletir retrospectivamente depois da ação. \\
\hline
\end{tabular}

Reconhecemos que desenvolver trabalho colaborativo fundamentado na abordagem reflexiva é complexo, pois depende de muitos fatores incluindo regularidade das interações construídas, acompanhamento constante e presencial dos professores, motivação deles em querer interagir de modo reflexivo, entre outros. No entanto, a abordagem reflexiva é fundamental para que o futuro professor desempenhe seu ofício sendo capaz, de modo autônomo, de analisar a situação de ensino-aprendizagem, de lidar com diferenças interculturais (incluindo as línguas), de adaptar as práticas de ensino ao público diverso e produzir seu próprio material pedagógico [...] (GRANDCOLAS \& VASSEUR, 1999, p. 5). Sob perspectiva semelhante, Kaneko-Marques (2011, p. 60) aponta que [...] a prática pedagógica, mobilizada pela reflexão, serviria como instrumento fundamental para a 
teorização a partir da prática. Para Shulman (1987, p. 11), investigar o trabalho de profissionais em sua prática diária é uma das tarefas mais importantes para a comunidade de pesquisa, pois dessa forma é possível sistematizar saberes que podem servir de inspiração para outros da área. Esse mesmo autor elenca sete saberes do professor que, no mínimo, deveriam fazer parte de um conjunto de conhecimentos base. Tomamos como referência o quadro elaborado por Izaki Gómez (2018) em que realiza traduções dos saberes que compõem os conhecimentos base propostos por Shulman (1987):

Figura 2. Izaki Gómez (2018, p. 36-37)

\begin{tabular}{|c|c|}
\hline \multicolumn{2}{|c|}{ Quadro 2 - Conhecimentos base } \\
\hline Original & Tradução \\
\hline Content Knowledge. & Conhecimento do conteúdo; \\
\hline $\begin{array}{l}\text { General pedagogical knowledge, with } \\
\text { special reference to those broad principles } \\
\text { and strategies of classroom management } \\
\text { and organization that appear to transcend } \\
\text { subject matter. }\end{array}$ & $\begin{array}{l}\text { Conhecimento pedagógico geral, com } \\
\text { referência especial aos princípios e } \\
\text { estratégias gerais de gerenciamento e } \\
\text { organização da sala de aula, que parecem } \\
\text { transcender o objeto da disciplina. }\end{array}$ \\
\hline $\begin{array}{l}\text { Curriculum knowledge, with particular } \\
\text { grasp of the materials and programs that } \\
\text { serve as "tools of the trade"for teachers. }\end{array}$ & $\begin{array}{l}\text { Conhecimento do currículo, com uma } \\
\text { compreensão particular dos materiais e } \\
\text { programas que servem como } \\
\text { "ferramentas do ofício"para professores. }\end{array}$ \\
\hline $\begin{array}{l}\text { Pedagogical content knowledge, that special } \\
\text { amalgam of content and pedagogy that is } \\
\text { uniquely the province of teachers, their own } \\
\text { special form of professional understanding. }\end{array}$ & $\begin{array}{l}\text { Conhecimento pedagógico do conteúdo, esse } \\
\text { amálgama especial de conteúdo e pedagogia } \\
\text { que é do domínio dos professores, sua própria } \\
\text { forma especial de compreensão profissional. }\end{array}$ \\
\hline $\begin{array}{l}\text { Knowledge of learners and their } \\
\text { characteristics. }\end{array}$ & $\begin{array}{l}\text { Conhecimento de aprendentes e suas } \\
\text { características. }\end{array}$ \\
\hline $\begin{array}{l}\text { Knowledge of educational context, ranging } \\
\text { from the workings of the group or classroom, } \\
\text { the governance and financing of school } \\
\text { districts, to the character of communities } \\
\text { and cultures. }\end{array}$ & $\begin{array}{l}\text { Conhecimento de contextos educacionais, } \\
\text { desde o funcionamento do grupo ou da sala } \\
\text { de aula, a gestão e financiamento das escolas } \\
\text { distritais, até o caráter das comunidades e } \\
\text { culturas. }\end{array}$ \\
\hline $\begin{array}{l}\text { Knowledge of educational ends, purposes, and } \\
\text { values, and their philosophical and historical } \\
\text { grounds. }\end{array}$ & $\begin{array}{l}\text { Conhecimento de finalidades, propósitos e } \\
\text { valores educacionais, e seus fundamentos } \\
\text { filosóficos e históricos. }\end{array}$ \\
\hline
\end{tabular}

Com base nas informações constantes nessa figura, o professor necessita conhecer não só o conteúdo que está ensinando, mas também questões pedagógicas gerais (organização da sala e gerenciamento da aula), institucionais (currículo e projeto pedagógico da instituição) e educacionais (princípios, filosofia de ensino e contexto sociocultural do entorno). Além disso, conhecer os aprendentes também é parte essencial desse processo. Esses conhecimentos base, constantes na figura 2, não são definitivos, já que o professor pode repensar, reorganizar, reconstruir tais saberes ao longo da docência (SHULMAN, 1987, p. 12). 
No Modelo de Operação Global de Ensino de Línguas, proposto por Almeida Filho (2005), há também representação das dimensões constituintes do processo de ensino, incluindo: Abordagem de ensino (concebida como "filosofia de trabalho"), Planejamento de curso, Seleção e Elaboração de Materiais, Método (experiência na língua-alvo) e Avaliação. Podemos, conceber tais dimensões como saberes que o professor precisa, no mínimo, apreender para exercer a docência. Nesse Modelo Global, há indicação de reflexão como parte integrante e, portanto, primordial do processo de ensino de línguas.

Levando em consideração a importância do processo de reflexão para reconstruir os saberes docentes, para os propósitos deste artigo, apresentaremos significados construídos na interação do par mais experiente com professores de PLE em formação no processo reflexãosobre-a ação. Para compreendermos como essa interação foi realizada, o contexto de coleta de dados será explicitado na seção a seguir.

\section{Metodologia}

Os dados que serão apresentados neste artigo foram analisados sob o referencial metodológico de natureza qualitativa de base etnográfica e interpretativista. Para Denzin e Lincoln $(2005$, p. 3), [...] a pesquisa qualitativa é uma atividade situada que localiza o observador no mundo. Consiste em um conjunto de práticas interpretativas e materiais que tornam o mundo visível. Esses autores destacam que os pesquisadores qualitativos estudam as coisas em suas configurações naturais (DENZIN e LINCOLN, 2005, p.3). Além disso, o interesse está no significado que se constrói no processo de investigação.

Em relação às configurações naturais descritas por Denzin e Lincoln (2005), podemos apontar como ambiente natural de coleta de dados a sala de aula dos cursos de PLE e da disciplina optativa da referida área, ambos desenvolvidos em uma universidade pública do interior paulista.

Os cursos de PLE fazem parte de um Centro de Referência de Português para Estrangeiros desde 1994 e são oferecidos semestralmente, no âmbito de Projeto de Extensão do Departamento de Letras da instituição. Esses cursos são ministrados em dupla, em sua maioria, por graduandos em Letras e têm carga horária de 45 horas. As aulas ocorrem duas vezes por semana e têm duração de 1h40. Os cursos oferecidos são: Básico 1 para falantes de outras línguas (B1FOL); Básico 1 para falantes de espanhol (B1FE); Básico 2 para falantes de outras línguas (B2FOL); Básico 2 para falantes de espanhol (B2FE); Intermediário 1; Intermediário 2; Avançado 1; e Avançado 2. 
Os ministrantes dos cursos são também alunos da disciplina optativa intitulada "Ensino de Português para Estrangeiros: contextos e práticas". De acordo com a ementa da referida disciplina, o objetivo é promover o desenvolvimento de capacitação para atuar no ensino de português para estrangeiros, a partir de conhecimento, discussão e reflexões envolvendo especificidades contextuais, materiais didáticos e componentes da prática pedagógica da área. Além da atuação desses graduandos, há participação também de pós-graduandos e outros colaboradores de áreas afins.

Os espaços de coleta de dados foram a sala de aula dos cursos de PLE, da disciplina optativa e o local onde as interações do par mais experiente com os professores em formação eram realizadas.

No tocante aos instrumentos utilizados, incluímos questionários semi-estruturados, gravação em áudio das interações e das aulas de PLE, diário do pesquisador e relatório elaborado pelos alunos da disciplina optativa. Para os interesses deste artigo, serão destacadas somente as interações do par mais experiente com os professores em formação.

Com relação aos participantes da referida pesquisa, retomamos a seguir o quadro elaborado na tese:

Figura 3. Izaki Gómez (2018, p. 105)

\begin{tabular}{|c|l|l|}
\hline \multicolumn{3}{|c|}{ Quadro 9 - Participantes da pesquisa } \\
\hline Contexto & \multicolumn{1}{|c|}{ Professores } & Alunos estrangeiros \\
\hline & $\begin{array}{l}19 \text { (em formação e alunos da } \\
\text { disciplina optativa de PLE - } \\
\text { PF1 a PF19). }\end{array}$ & 28 ( A1 a A28) \\
Brasileiro & $\begin{array}{l}\text { 1 (pós-graduando - PG20). } \\
\text { Pesquisador (como par mais } \\
\text { experiente). }\end{array}$ & \\
\hline Total & \multicolumn{2}{|c|}{$\mathbf{2 1}$} \\
\hline \multicolumn{2}{|c|}{ Fonte: Próprio autor. } \\
\hline
\end{tabular}

Com base na descrição representada na Figura 3, participaram 21 pessoas: 19 professores em formação e alunos da disciplina optativa, 1 pós-graduando e 1 pesquisadora. Embora os alunos estrangeiros também fizessem parte da pesquisa, neste artigo não levaremos em consideração os dados produzidos durante a participação deles. 
As interações com o par mais experiente foram construídas ao longo do segundo semestre de 2014 e do primeiro semestre de 2015. A frequência dessa reunião está registrada no quadro a seguir:

Figura 4. Izaki Gómez (2018, p. 126)

Quadro 12 - Frequência de observação das aulas e de interação.

\begin{tabular}{|l|c|c|}
\hline \multicolumn{1}{|c|}{ Curso de PLE } & $\begin{array}{c}\text { Data de observação } \\
\text { da aula }\end{array}$ & Interação com o par mais experiente \\
\hline Intermediário 1 & $23 / 09 / 2014$ & $30 / 09 / 2014$ \\
\hline $\begin{array}{l}\text { Básico 2 para Falantes } \\
\text { de Espanhol (Turma A) }\end{array}$ & $24 / 09 / 2014$ & $29 / 09 / 2014$ \\
\hline $\begin{array}{l}\text { Básico 2 para Falantes } \\
\text { de Espanhol (Turma B) }\end{array}$ & $29 / 09 / 2014$ & $14 / 10 / 2014$ \\
\hline $\begin{array}{l}\text { Básico 1 para Falantes } \\
\text { de espanhol }\end{array}$ & $2 / 10 / 2014$ & $17 / 10 / 2014$ \\
\hline Intermediário 1 & $07 / 10 / 2014$ & $\begin{array}{c}\text { Não houve a } \\
\text { segunda reunião }\end{array}$ \\
\hline Avançado 2 & $07 / 10 / 2014$ & $24 / 09 / 2014$ \\
\hline $\begin{array}{l}\text { Básico 2 para Falantes } \\
\text { de Espanhol (Turma A) }\end{array}$ & $15 / 10 / 2014$ & $\begin{array}{c}\text { Não houve a } \\
\text { segunda reunião }\end{array}$ \\
\hline $\begin{array}{l}\text { Intermediário 1 } \\
\text { (curso de 2015) }\end{array}$ & $05 / 05 / 2015$ & Não houve reunião \\
\hline
\end{tabular}

Fonte: Próprio autor.

Foi possível observar todos os cursos constantes nessa descrição e as interações com as duplas de professores ocorreram com a maioria deles pelo menos uma vez. Esclarecemos que a interação com todos os professores ministrantes ocorreu na sala de aula da disciplina optativa.

Conhecido o contexto de coleta de dados, apresentaremos a seguir a análise construída na referida tese destacando a reflexão-sobre-a ação.

\section{Significados construídos na Reflexão-Ação}

Podemos considerar que as interações do par mais experiente com os professores em formação produziram significados relevantes para o contexto do ensino e aprendizagem de línguas e, especificamente, de PLE. Dentre os significados construídos, destacamos três categorias para análise e discussão neste artigo: Aspecto temporal: o período (não)dedicado 
para elaboração do material; Dificuldade na seleção e elaboração de materiais; e Atuação do par mais experiente.

Durante as interações, foi verificado que os professores em formação alegaram não ter tempo para elaborar parte do material para as aulas. Essa informação pode ser visualizada na figura a seguir:

Figura 5. Izaki Gómez (2018, p. 160)

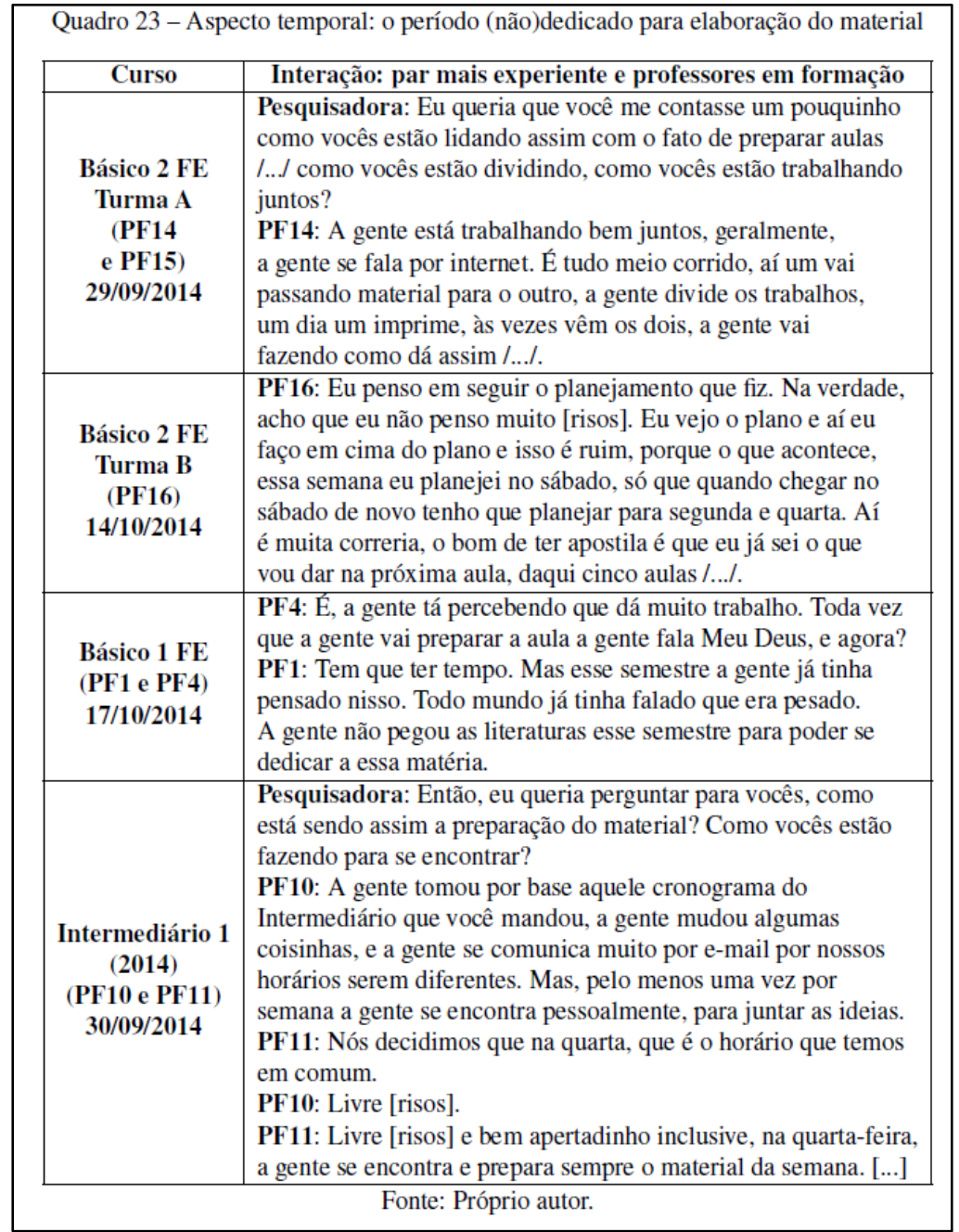

Com base nessas respostas, averiguamos que os professores em formação se dedicavam à elaboração de parte do material nas horas livres. De acordo com Almeida Filho (2005), as dimensões "Elaboração e Seleção de Materiais" e "Método" são altamente relevantes para o processo de ensino, o que implica, dentre outros fatores, tempo e reflexão para realizar as tarefas com qualidade. 
Dentre os professores, apenas PF16 declarou expressamente não refletir sobre essas dimensões: Eu penso em seguir o planejamento que fiz. Na verdade, acho que eu não penso muito [risos]. Para Grandcolas e Vasseur (1999), Leffa (2001), Almeida Filho (2005), Zeichner (2008), Kaneko-Marques (2011), entre outros, a reflexão é parte essencial na formação de professores e, portanto, necessita ser desenvolvida em ação colaborativa com pelo menos um par mais experiente. Retomando os pressupostos bakhtinianos, é na interação que construímos significados e nos constituímos como sujeitos. Nesse sentido, o professor em formação necessita de acompanhamento constante e de interação com um par mais experiente para colaborar na ressignificação de sua prática pedagógica.

A falta de tempo na preparação de parte do material acarretou dificuldade em sua seleção e elaboração. Muitos professores informaram ter dificuldades em relação a esse tema, como pode ser constatado a seguir:

Figura 6. Izaki Gómez (2018, p. 164)

\begin{tabular}{|c|c|c|c|}
\hline \multicolumn{2}{|r|}{ Quadro 24 - Dificuldade na seleção e elaboração de materiais } & & \\
\hline Curso & Interação: par mais experiente e professores em formação & & \\
\hline \multirow[b]{2}{*}{$\begin{array}{c}\text { Básico } 2 \text { FE } \\
\text { Turma A } \\
\text { (PF14 } \\
\text { e PF15) } \\
29 / 09 / 2014\end{array}$} & \multirow{2}{*}{$\begin{array}{l}\text { PF14: A gente também tá meio inseguro para fazer material, } \\
\text { porque no espanhol da universidade por exemplo tem uma } \\
\text { cobrança que tem que ser tudo original, então, a gente não } \\
\text { pode fazer. A gente tem essa insegurança nesse sentido } \\
\text { também. } \\
\text { Pesquisadora: Original, como assim? } \\
\text { PF14: Porque a gente não pode a gente fazer um exercício, } \\
\text { tem que ser um contexto verdadeiro. } \\
\text { Pesquisadora: Ah, a gente também aqui [risos]. No caso seria } \\
\text { o que a gente fala de material autêntico que é, ou você pega } \\
\text { notícia de jornal, na internet vídeos, isso já é material autêntico, } \\
\text { música. } \\
\text { PF14: É que na outra turma eles fizeram um textinho assim, } \\
\text { eles mesmos, aí a gente não quis arriscar, porque seria para aula } \\
\text { e não seria autêntico né. } \\
\text { Pesquisadora: Isso, isso tem uma questão quando você prepara } \\
\text { para fim especíico, não é autêntico. } \\
\text { PF14: Então, é melhor pegar alguma coisa pronta? } \\
\text { Pesquisadora: Um material autêntico. } \\
\text { PF14: Um material autêntico e dai fazer algumas questões. } \\
\text { Pesquisadora: Isso, aí preparar uma atividade com materiais } \\
\text { autênticos. A gente não aconselha usar assim textos } \\
\text { elaborados para esses fins específicos, porque é você que está } \\
\text { elaborando, então, é você que está usando, manipulando a } \\
\text { linguagem para aquele fim específico então não é autêntico, } \\
\text { o aluno não vai encontrar isso em outro lugarl..J Mas, eu } \\
\text { preciso ver com eles, qual foi o contexto que eles trabalharam } \\
\text { isso, como foi feito, mas a gente não aconselha trabalhar isso } \\
\text { não, né. Mas isso aconteceu só com esse exercício ou vocês já } \\
\text { vinham pegando uma atividade em algum livro já pronta e já } \\
\text { aplicando na sala sem ter visto antes? } \\
\text { PF14: Geralmente, a gente lê antes, nunca tinha dado problema } \\
\text { assim, acho por esse tema ser mais gramatical que deu problema, } \\
\text { porque até então a gente tava trabalhando coisa mais comunicativa, } \\
\text { aí não tinha dado nenhum problema. A gente lia e falava tudo bem. }\end{array}$} & $\begin{array}{c}\text { Básico 2 FE } \\
\text { Turma B } \\
\text { (PF16) } \\
\text { 14/10/2014 }\end{array}$ & $\begin{array}{l}\text { Pesquisadora: Então, você não produz as atividades por meio de } \\
\text { algum tema? Porque isso facilita tanto. } \\
\text { PF16: Por meio de temas que já estão no planejamento /... o o que } \\
\text { eu quero falar é que o bom da apostila, como já tá segmentado, você } \\
\text { não fica com aquela preocupação ai e agora meu Deus na próxima } \\
\text { aula o que eu vou fazer, porque eu fico assim, toda semana /.... Para } \\
\text { mim é melhor ter uma apostila, mas eu preciso de um dia para } \\
\text { preparar essa apostila e deixar ela no jeito já. E dá trabalho né? /.../ } \\
\text { Preciso achar um tempo aí só para isso. }\end{array}$ \\
\hline & & $\begin{array}{c}\text { Básico 1 FE } \\
\text { (PF1 e PF4) } \\
17 / 10 / 2014\end{array}$ & $\begin{array}{l}\text { Pesquisadora: Na disciplina, vocês responderam ao questionário sobre } \\
\text { desafios e naquele momento era diferente porque vocês não conheciam } \\
\text { seus alunos, agora, que vocês conhecem os seus alunos, vocês acham } \\
\text { que os desafios continuam? Ou quais são esses desafios? } \\
\text { PF1: A gente teve muita sorte ... Eles entendem muito bem. A cultura } \\
\text { não é tão diferente. Mas, eles falam tão bem, eles têm muito contato. } \\
\text { Então, a gente tem facilidade nessa parte. } \\
\text { PF4: Tanto da cultura, de lidar mesmo com os alunos, são quatro alunos, } \\
\text { né. Assim, está sendo tranquilo nessa parte. Uma coisa que a gente mais } \\
\text { tem dificuldade é na hora de preparar a aula. Porque às vezes a gente } \\
\text { olha no programa e como a gente vai encaixar a sistematização dentro } \\
\text { da matéria /..J tem dia que a gente fica um dia inteiro preparando aula, } \\
\text { na sexta-feira, praticamente é a sexta-feira inteira preparando aula da } \\
\text { outra semana. A gente sempre tá correndo atrás de vídeo, de música, } \\
\text { alguma coisa que a gente pode inserir para mostrar a sistematização, } \\
\text { que é o Mais difícil que a gente tá sofrendo um pouquinho ainda. } \\
\text { Mas do resto está sendo bem tranquilo. /..J A gente fica vendo o } \\
\text { pessoal na sala comentar [na disciplina optativa de PLE] que os } \\
\text { colombianos têm mais dificuldade para entender,e a gente tem um } \\
\text { aluno colombiano e ele não tem dificuldade. A gente teve muita sorte. }\end{array}$ \\
\hline \multicolumn{2}{|r|}{ Continua na página seguinte. } & \multicolumn{2}{|r|}{ Fonte: Próprio autor. } \\
\hline
\end{tabular}


Segundo as informações constantes na figura 6, PF14 declara que geralmente lê o material preparado para aula. No entanto, o material selecionado gerou dúvida tanto nos alunos quanto nos professores. Esse fato desestabilizou o gerenciamento e a organização da aula. Verificou-se também que os professores em formação concebem as dimensões "Elaboração e Seleção de Materiais" e "Método" como saberes complexos para lidar durante a prática. Para Shulman (1987, p. 11), a sabedoria didática é a menos sistematizada nas investigações, mesmo sendo, para esse autor, uma das tarefas mais significativas para a comunidade científica. Nessa perspectiva, o trabalho colaborativo com um par mais experiente, no acompanhamento da prática pedagógica de professores em formação, foi fundamental para analisar as dificuldades e propor encaminhamentos. Além disso, durante as interações, a reflexão sobre o ensino e aprendizagem de PLE pôde ser construída colaborativamente, possibilitando a criação de um espaço profícuo de reflexão sobre a prática pedagógica. Esse dado pode ser consultado a seguir:

Figura 7. Izaki Gómez (2018, p. 165-166)

\begin{tabular}{|c|c|c|}
\hline \multicolumn{3}{|c|}{ Quadro 25 - Ações do par mais experiente } \\
\hline Curso & Diário do pesquisador & Interação: par mais experiente e professores em formação \\
\hline $\begin{array}{c}\text { Básico 2 FE } \\
\text { Turma A } \\
\text { (PF14 } \\
\text { e PF15) }\end{array}$ & $\begin{array}{l}\text { Sugestões: Repensar o lugar } \\
\text { da gramática na sala de aula: } \\
\text { evitar ocupar muito tempo da } \\
\text { aula com conjugação de verbos } \\
\text { ou com atividades muito } \\
\text { estruturais. Elaborar } \\
\text { estratégias para tentar amenizar } \\
\text { a quantidade de dúvidas } \\
\text { com vocabulário (enviar o texto } \\
\text { no grupo do facebook para os } \\
\text { alunos pesquisarem possíveis } \\
\text { dúvidas). Antes de aplicar uma } \\
\text { atividade já existente, tentar } \\
\text { fazer para verificar seu } \\
\text { funcionamento. }\end{array}$ & $\begin{array}{l}\text { Pesquisadora: E outra coisa que a gente pode pensar como estratégia para } \\
\text { controlar esse grupo é já no início da aula, [...] falar qual é o propósito } \\
\text { dessa aula. /.../ Se for realmente uma atividade, explicar a sequência } \\
\text { da atividade, qual o propósito disso, porque talvez eles fiquem um } \\
\text { pouco mais assim seguros do que vai ser estudado para aquela aula } \\
\text { e para que que vai ser. /.../ Também igual do Cazuza que vocês trabalharam, } \\
\text { teve bastante dúvida com o vocabulário, então, pensar em estratégias } \\
\text { para a gente não ficar tanto tempo tirando dúvida de vocabulário também. } \\
\text { Como a gente podia fazer nesse caso de trabalhar essa música do Cazuza? } \\
\text { PF14: Talvez, separar já algumas palavras que a gente imagine que vá } \\
\text { gerar dúvidas. } \\
\text { Pesquisadora: Então, essa de separar palavras também é um pouco ruim } \\
\text { porque parece que a gente já está pressupondo que não consegue, né. } \\
\text { /.../. Nesse caso, não sei, se podia já mandar a letra no grupo para eles /.../ } \\
\text { mandar pelo face[facebook] para eles ouvirem, quem sabe em } \\
\text { casa ir atrás de alguns vocabulários, porque aí já fica uma tarefa para eles } \\
\text { também, né, deles pesquisarem e de vocês não darem tudo sempre. }\end{array}$ \\
\hline $\begin{array}{c}\text { Básico 2 FE } \\
\text { Turma B } \\
\text { (PF16) }\end{array}$ & $\begin{array}{l}\text { Sugestões:[...] Sistematizar as produções } \\
\text { orais de modo que os alunos } \\
\text { possam elaborar pequenas apresentações } \\
\text { para a sala e os professores avaliarem o } \\
\text { desempenho do aluno (usar } \\
\text { a grade do Celpe-Bras, } \\
\text { por exemplo). }\end{array}$ & $\begin{array}{l}\text { Pesquisadora: Eu não cheguei a passar a grade do entrevistador e do } \\
\text { observador para vocês, porque isso é um parâmetro que a gente pode } \\
\text { usar para poder avaliar. Então, você fez a avaliação oral, no caso do } \\
\text { observador, você pode avaliar seis critérios /.... Então, são seis } \\
\text { critérios que a gente avalia quando tá fazendo a prova do Celpe-Bras } \\
\text { na entrevista. E são critérios que você pode usar para comentar, } \\
\text { você partiu de onde para poder avaliar cada aluno /.../. Isso é bom } \\
\text { porque estrutura bem né, critérios claros para orientar a sua avaliação. } \\
\text { Isso eu não comentei em sala. } \\
\text { PF16: Não, você tem a tabela? } \\
\text { Pesquisadora: Eu tenho a tabela. [...] }\end{array}$ \\
\hline
\end{tabular}




\begin{tabular}{|c|c|c|}
\hline $\begin{array}{l}\text { Básico 1 FE } \\
\text { (PF1 e PF4) }\end{array}$ & $\begin{array}{l}\text { Sugestão: Evitar usar um } \\
\text { material autêntico só com fim } \\
\text { estrutural. Pensar sobre a } \\
\text { língua em uso, com } \\
\text { propósito comunicativo. }\end{array}$ & $\begin{array}{l}\text { Pesquisadora: /.../ A única coisa que eu anotei aqui, mas eu já falei, porque vocês } \\
\text { vieram perguntar, é em relação à música Cotidiano. A gente tenta evitar usar } \\
\text { um material autêntico, música, vídeo, qualquer outro material, } \\
\text { com aquele fim específico que explorar alguma estrutura da língua. } \\
\text { Então, eu percebi que quando vocês passaram a música, foi com ou } \\
\text { sem som? } \\
\text { PF1: O primeiro foi sem som. Primeiro para eles completarem e } \\
\text { depois com o som. } \\
\text { Pesquisadora: Então, já tinham os verbos indicados. Então, não } \\
\text { precisava da música. } \\
\text { PF4: Entendi. } \\
\text { PF1: Mas a gente até mudou. } \\
\text { PF4: A gente está tentando explorar bastante coisa mesmo do social, } \\
\text { alguma coisa que retrate a sociedade brasileira. /.../ } \\
\text { Pesquisadora: Porque eles não precisariam entender o contexto da } \\
\text { música, o significado da música, era só pegar o verbo e conjugar. } \\
\text { PF1: Esse foi um erro que, particularmente, pequei, porque eu aprendi } \\
\text { inglês assim. A gente quis adaptar a mesma coisa, mas não dá. É } \\
\text { diferente. }\end{array}$ \\
\hline $\begin{array}{c}\text { Intermediário } 1 \\
\text { (2014) } \\
\text { PF10 e PF11 }\end{array}$ & $\begin{array}{l}\text { Sugestões: Não há } \\
\text { necessidade de falar } \\
\text { mais devagar } \\
\text { no Intermediário. } \\
\text { /.../ As conjugações realizadas na } \\
\text { lousa poderiam ser lição de casa ou } \\
\text { enviadas pelo grupo no facebook. }\end{array}$ & $\begin{array}{l}\text { Pesquisadora: /.../ A ideia é sempre falar o português, } \\
\text { não precisa falar devagar ou pausadamente, } \\
\text { O que eu percebi PF11 é que você fala muito devagar em alguns momentos } \\
\text { justamente pelo falante de outras línguas. } \\
\text { PF11: Isso. } \\
\text { Pesquisadora: Não precisa. } \\
\text { PF11: Não precisa né. } \\
\text { Pesquisadora: Vamos pensar assim. É intermediário 1, então, não precisa pausar } \\
\text { tanto. /.../ } \\
\text { PF11: No grupo, até para que o aluno se esforce /.../ } \\
\text { Pesquisadora: Isso, seguir o seu ritmo. Tanto que no Celpe-Bras tem lá fluxo } \\
\text { natural da fala, compreensão do fluxo natural da fala, né, acho que nenhum de } \\
\text { vocês tem a fala muito corrida. }\end{array}$ \\
\hline
\end{tabular}

Como explicitado na parte da metodologia, o diário do pesquisador não será levado em consideração para esta análise. No entanto, informamos que a pesquisadora observava as aulas ministradas pelos professores em formação e as registrava no diário. Esse instrumento era dividido em três partes: observação preliminar, observação final e sugestões. Na figura 7 , constam as sugestões realizadas que embasavam parte das interações do par mais experiente com os professores. Durante a interação, PF1 pôde perceber, por meio do olhar de outro sujeito (o par mais experiente) sobre a sua prática, que estava reproduzindo saberes construídos em outros contextos que, para os pressupostos orientadores do ensino de PLE, não se aplicavam satisfatoriamente para a sala de aula da referida área. A reflexão em conjunto permitiu que PF1 ressignificasse a sua prática de modo a não utilizar a canção Cotidiano somente para preencher lacunas com verbos. Na interação, PF1 e PF4 informam: Mas a gente até mudou (PF1) / A gente está tentando explorar bastante coisa do social mesmo, alguma coisa que retrate a sociedade brasileira (PF4). Foi nesse espaço dialógico que a reflexão-sobre-a ação foi construída. Nesse sentido, o par mais experiente:

[...] atuou como mediador no processo de ensino de PLE, contribuindo de modo relevante para que o professor em formação pudesse potencializar seu conhecimento a partir das discussões construídas naquele espaço. Como pontuou Vieira-Abrahão (2012, p. 462-463) nessa participação guiada há 
ação conjunta de um iniciante e um par mais competente no desenvolvimento de uma tarefa. Levando em consideração o contexto analisado de ensino de línguas, a tarefa é altamente complexa para os professores em formação, o que demanda participação direta e constante de, pelo menos, um par mais experiente. Constatamos que esses professores em formação enfrentavam dificuldades com relação às duas dimensões seleção e elaboração de materiais e método, afetando o gerenciamento e a organização da aula/atividade na prática pedagógica, denominado conhecimento pedagógico geral, segundo estudos de Shulman (1987). (IZAKI GÓMEZ, 2018, p. 167)

Como as aulas geralmente eram ministradas em dupla, os professores e a pesquisadora interagiam construindo significados em ação colaborativa, como pode ser constado na transcrição a seguir:

Curso Intermediário $1(30 / 09 / 2014)$

PF11: Só voltando que você falou dos desafios, eu fico um pouco confuso em relação ao regionalismo também. Porque a gente sabe que no Brasil são milhares de países num só. Então, eu sou lá do Pará. Então, toda hora a gente tá fazendo essa diferença.

PF10: Mas, eu acho muito legal para os alunos porque eles estão aqui tendo contato com a língua com um dos professores daqui e o PF11 de lá que usa o tu, que fala diferente, que tem o " $\mathrm{r}$ " diferente, o "s" diferente, eu acho muito legal, e eles perguntam /.../ acho que tá super legal essa troca, acho que tá sendo bem proveitoso para eles terem esse contato com o mesmo idioma e com sotaques diferentes.

PF11: Mas, às vezes, eu fico assim, será que a gente não tá perdendo muito tempo da aula para explicar que na região tal é assim, será que isso é tão relevante, né, eu fico um pouco na dúvida /.../.

Pesquisadora: Não, é importante sim, porque vocês falarem isso que tem diferença mesmo de região para região, porque eles vêm com a ideia, não sei se eles chegaram a perguntar, mas qual é o correto? Não chegaram a pergunta ainda?

PF11: Não.

/.../

PF10: Mas, PF11 eu acho isso bem legal porque na minha experiência na Argentina /.../ e anualmente, vem um grupo do Rio Grande do Sul que vai para a universidade /.../ aí, a gente conversando, teve uma hora, um momento que eu falei assim, porque no Brasil é assim. Aí o gaúcho virou para mim e falou assim, em São Paulo é assim, não é no Brasil /.../. Eu nunca tinha parado para pensar nisso. Então, é bem interessante de ter mesmo essas distinções porque senão eles vão embora com a visão daqui que o Brasil é isso. E não é.

Com base nesses dados, percebemos o quão relevante é criar espaços para que a reflexão possa ser construída em ação colaborativa não só com o par mais experiente, mas também com outro(s) professor(es). A percepção de PF10 sobre a inquietação de seu colega de trabalho, PF1, foi potencialmente significativa. Retomando os estudos bakhtinianos, é na interação que nos constituímos como sujeitos e produzimos sentidos, os quais não seria possível realizar sozinho. Levando em consideração o contexto analisado, foi proposta por Izaki Gómez (2018) a figura a seguir:

Figura 8. Izaki Gómez (2018, p. 169) 


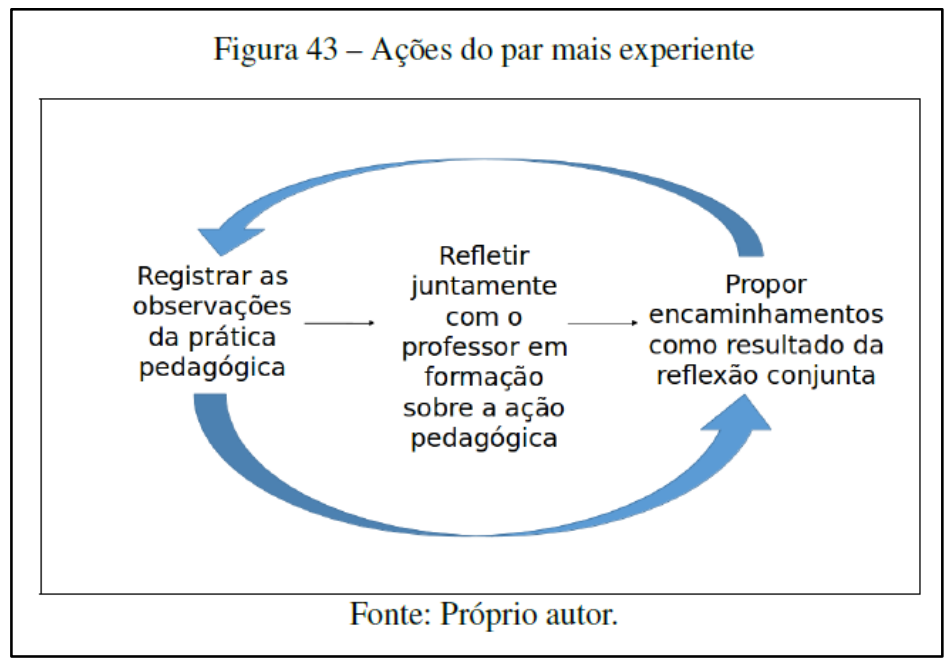

As ações que podem ser realizadas por um par mais experiente são descritas por Izaki Gómez (2018, p. 169) no excerto a seguir:

\begin{abstract}
Antes de acompanhar os professores em formação na prática pedagógica, é necessário primeiramente conhecer as perspectivas em relação ao ensino de PLE desses professores. Assim como pontuou Shulman (1987) no tocante aos conhecimentos base, o conhecimento de aprendiz e suas características faz parte do saber docente e, portanto, reconhecemos que se configura como etapa imprescindível para o desenvolvimento de prática reflexiva. Nessa etapa, o par mais experiente pode aplicar questionário com perguntas acerca do processo de ensino de PLE incluindo: concepção de ensino, de língua, de aprendiz, de material, entre outros. Posteriormente, esses dados podem ser contrastados com a prática para verificação da relação teoria e prática e/ou o dizer e o fazer pedagógicos. Em seguida, o par mais experiente acompanha as aulas desses professores em formação e registra suas observações, por meio de gravação em áudio, diário, entre outros instrumentos. Esse registro é imprescindível para a construção de espaço dialógico e, posteriormente, para os encaminhamentos. De modo contínuo, o par mais experiente e o professor em formação poderão produzir significados relevantes sobre a prática na sala de aula e, desse modo, refletir durante o processo de ensino.
\end{abstract}

O trabalho do par mais experiente é complexo, mas indispensável para auxiliar na formação de professores de línguas em geral e, especificamente, de PLE. A ação colaborativa entre os envolvidos é potencialmente significativa para o desenvolvimento da reflexão e da autonomia do professor em formação. Cabe perguntarmos se os cursos de Licenciatura em Letras estão provendo esse espaço de construção reflexiva mediada por, pelo menos, um par mais experiente e desenvolvendo esse acompanhamento de modo constante.

Levando em consideração a análise apresentada, discutiremos a seguir os encaminhamentos realizados como forma de atender às dificuldades dos professores em formação de PLE. 


\section{Conclusão}

Neste artigo, apresentamos três das categorias de análise que fizeram parte da pesquisa de doutorado, incluindo Aspecto temporal, Dificuldade na elaboração e seleção de materiais e Ações do par mais experiente. Verificamos que os professores em formação tinham dificuldades para elaborar e selecionar materiais para os cursos de PLE por falta de tempo (conforme alegaram) e pela complexidade dessas duas dimensões do Modelo de Operação Global de Ensino de Línguas, a saber: Elaboração e Seleção de Materiais e Método. Essas dificuldades acarretaram falta de organização e gerenciamento das aulas, constatados pela pesquisadora. Esses dois aspectos fazem parte do conhecimento pedagógico geral integrante dos sete saberes constituintes dos conhecimentos base propostos por Shulman (1987) e, portanto, altamente relevantes na formação de professores.

Durante as interações com o par mais experiente, averiguamos o quão importante é a ação de outro sujeito na construção da reflexão. Nesse sentido, foi proposto na pesquisa de doutorado o Saber Reflexivo-colaborativo, como conhecimento indispensável para a formação de professores, o qual retomamos a seguir:

Figura 9. Izaki Gómez (2018, p. 151)

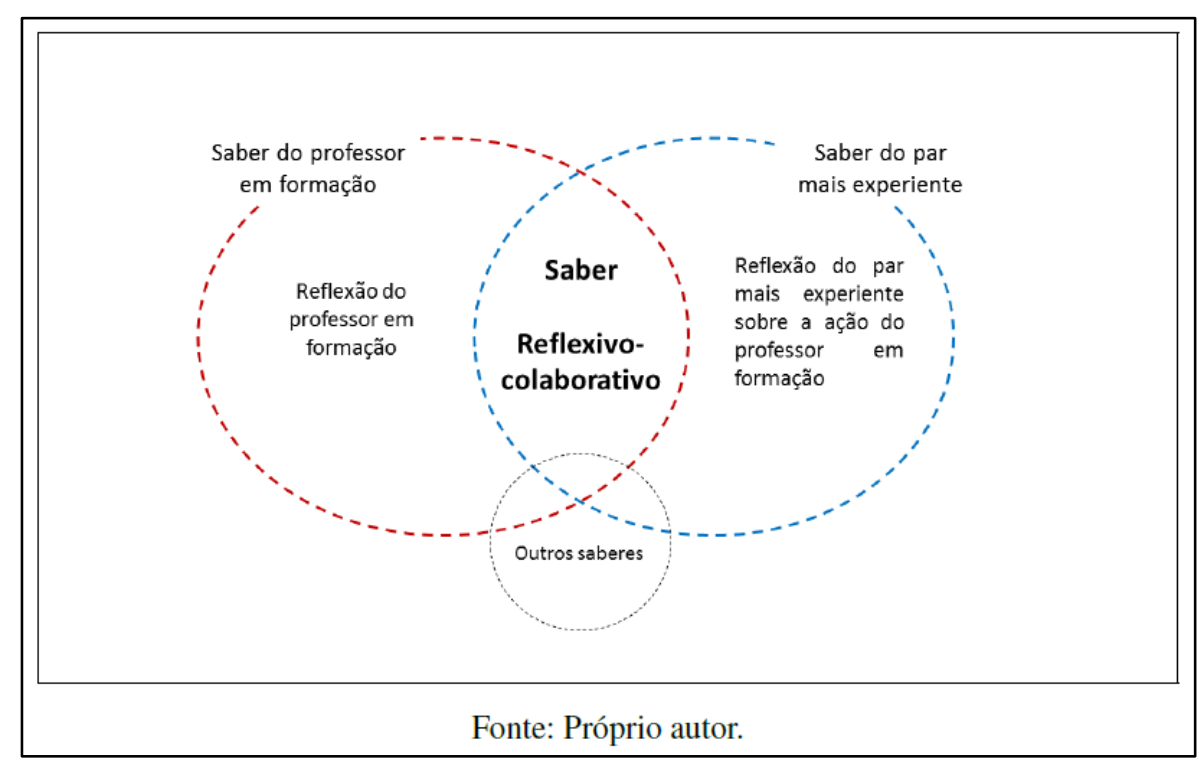

Com base nessa figura, podemos verificar que o saber do professor em formação também é levado em consideração no processo de reflexão. Juntamente com o saber do par 
mais experiente, o processo reflexivo é construído de modo colaborativo. Essa interação é fundamental para que o professor em formação possa ressignificar a sua prática a partir do olhar de outro(s) sujeito(s). Assim como pontuaram Libâneo (2006) e Schön (2000), a reflexão pode também ser realizada de maneira solitária. Já para Zeichner (2008), a reflexão é considerada ação social. A nosso ver, é importante que o professor em formação reflita consigo mesmo e também com outros professores. Como já discutido, a visão do outro sobre mim pode potencialmente colaborar para significação daquilo que eu não posso apreender sozinho.

A investigação da prática dos professores em formação pôde demonstrar algumas dificuldades discutidas neste artigo em relação ao ensino e aprendizagem de PLE. Averiguamos que os professores em formação alegaram falta de tempo na preparação do material para o curso, o que implicou dificuldade em elaborar e selecionar atividades para as aulas. Outro desdobramento dessa constatação foi a falta de organização e gerenciamento da aula. Essas evidências só foram possíveis de serem verificadas por meio da ação do par mais experiente. Embora a frequência das interações não ocorresse em grande escala, a atividade colaborativa produziu dados significativos para refletirmos sobre a formação de professores de PLE. Foi possível constatar também que esse trabalho de acompanhamento constante e construção de espaço reflexivo sobre o dizer e o fazer pedagógicos é tarefa complexa e necessita, portanto, de uma equipe de colaboradores. Nesse sentido, Izaki Gómez (2018) propôs um Organograma base de trabalho colaborativo em PLE: 


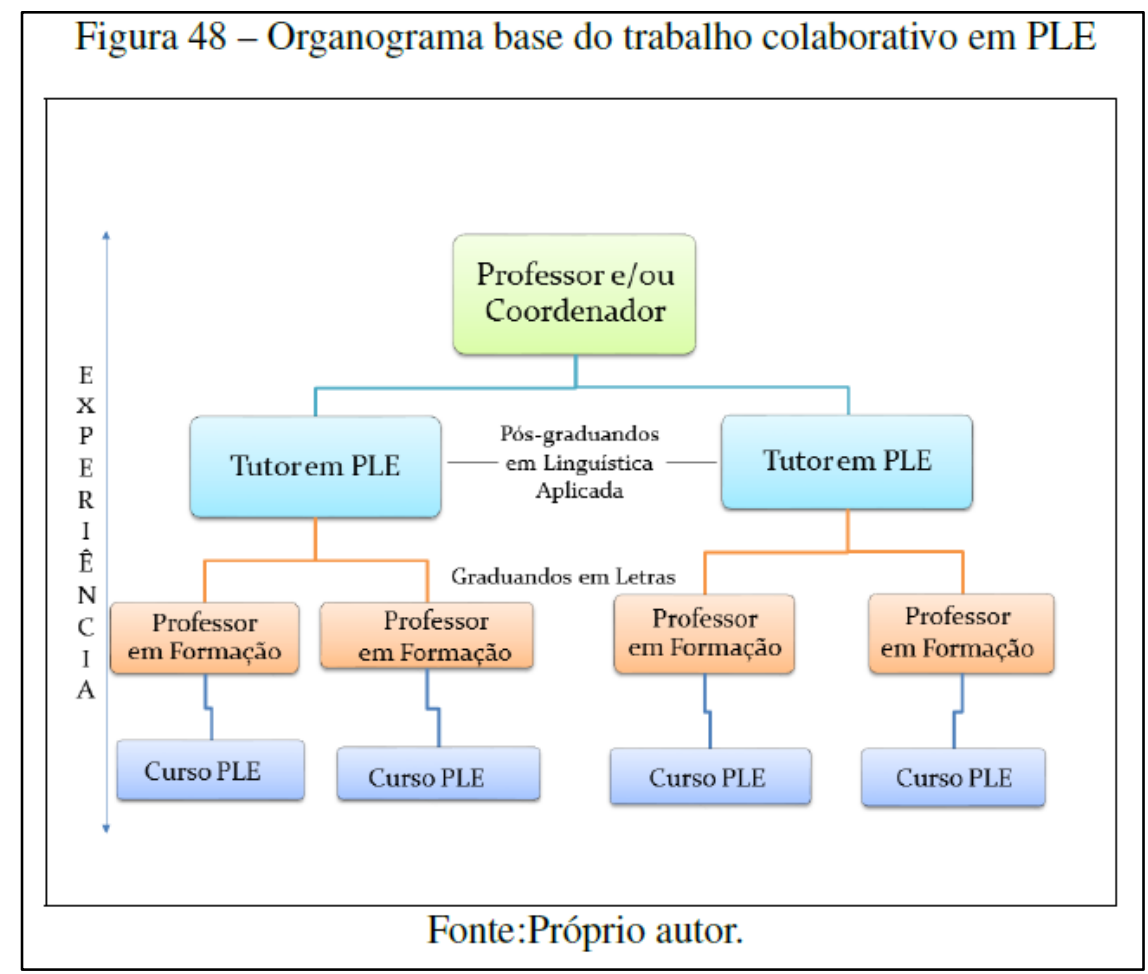

Nesse organograma, podemos visualizar três agentes: professor/coordenador dos cursos de PLE, tutor (pós-graduando) e professor em formação. A hierarquia representada se refere à experiência: professor>tutor>professor em formação. Levando em consideração a complexidade em coordenar cursos de PLE nas universidades, o professor/coordenador necessita de Tutores em PLE, ou seja, o par mais experiente. As funções de cada um desses agentes estão descritas a seguir:

O professor da disciplina e/ou coordenador dos cursos de PLE exerce a função de planejar e coordenar disciplina/cursos e orientar as ações teóricopedagógicas tanto do tutor quanto dos professores em formação. O tutor, como representado na figura 43 , tem o papel de observar as aulas, refletir com o professor em formação sobre a prática pedagógica e propor encaminhamentos por meio de ação em conjunto. É fortemente recomendável que o par mais experiente ou tutor seja pós-graduando da Linguística Aplicada (preferencialmente) e/ou tenha formação no ensino de línguas, com experiência no ensino de PLE/L2. É de relevância que a filosofia de trabalho esteja fundamentada em pressupostos contemporâneos (atualmente correspondendo a bases teóricas comunicativas e/ou socioculturais e/ou interculturais) em que a língua seja concebida como produção social, o ensino seja realizado com base em concepção reflexivocolaborativa e o aluno seja considerado agente ativo na/para construção do saber. Além disso, é importante que o par mais experiente ou tutor colabore na produção de conhecimento em/para PLE por meio de pesquisas acadêmicas. Sob a perspectiva comunicativa e sociocultural, ambos os 
agentes (coordenador e tutor) atuam como mediadores do processo de ensino e aprendizagem de PLE para que o Saber Reflexivo-colaborativo seja realizado de fato. (IZAKI GÓMEZ, 2018, p. 199-200)

O professor em formação tem a responsabilidade de ministrar as aulas, sob perspectiva reflexiva, o que implica domínio dos saberes docentes propostos por Tardif (2002) e Shulman (1987). Ao aluno estrangeiro, cabe avaliar os cursos para que suas percepções tenham efeito retroativo no processo de ensino e aprendizagem de PLE.

Nesse árduo percurso de (re)construção de saberes, tornam-se indispensáveis ação colaborativa, construção de espaço para reflexão, pares com mais experiência e equipe de trabalho para ressignificar o dizer e o fazer pedagógicos dos professores em formação de PLE e de línguas no geral.

Nesse sentido, corroboramos a ideia do espaço reflexivo como imprescindível na formação e defendemos que a participação de, pelo menos, um par mais experiente pode contribuir na construção do saber docente. Reconhecemos que a participação de outro sujeito tem papel fundamental na prática reflexiva, pois embora seja possível desenvolver uma reflexão sobre si mesmo, o processo pode não ser “completo”. É na interação com o outro que o sujeito-professor pode conhecer outras perspectivas e, desse modo, (re)construir a sua prática (IZAKI GÓMEZ, 2018, p. 50). Assim como a língua, o sujeito e o saber são construídos socialmente por meio da interação e a reflexão sobre o dizer e o fazer também necessita de ação colaborativa.

Com base na análise apresentada neste artigo, temos expectativa de que esta discussão possa colaborar para fomentar investigações no tocante à prática pedagógica de professores em formação de PLE e contribuir para reflexão sobre saberes docentes da referida área.

\section{REFERÊNCIAS BIBLIOGRÁFICAS}

ALMEIDA FILHO, J. C. P. Dimensões comunicativas no ensino de línguas. [S.1.] Campinas: Pontes, 2005.

BAKHTIN; VOLOCHÍNOV. Marxismo e filosofia da linguagem. 12ª.ed., [S.1.]: Hucitec: São Paulo, 2006.

BARBIRATO, R. d. C. Tarefas geradoras de insumo e qualidade interativa na construção do processo de aprender LE em contexto inicial adverso. Tese de doutorado. [sn], 2005. 
DENZIN, N. K.; LINCOLN, Y. S. The sage handbook of qualitafive research. Thousand Oaks, CA: Sage Publication, 2005, p. 695-728.

DUTRA, A. F. O processo reflexivo-colaborativo na formação inicial de professores de português língua estrangeira. UFMG, 2010.

GERALDI, J. W. Sobre a questão do sujeito. In: Ancoragens: estudos bakhtinianos. São Carlos: Pedro \& João Editores, 2010.

GRANDCOLAS, B.; VASSEUR, M.-T. Conscience d'enseignant, conscience d'apprenant: réflexions interactives pour la formation. [S.1.]: Socrates/lingua, 1999.

IVIC, I.; COELHO, E. P. Lev Semionovich Vygotsky. [S.1.]: Fundação Joaquim Nabuco, 2010.

IZAKI GÓMEZ, M. A. Saberes docentes e desafios no ensino de Português Língua Estrangeira na atuação de professores em formação. Tese (doutorado)-Universidade Federal de São Carlos, campus São Carlos, 2018.

KANEKO-MARQUES, S. M. O processo de (re) construção da prática pedagógica de professores de língua inglesa em formação inicial. Tese de doutorado. Universidade Estadual Paulista (UNESP), 2011.

LEFFA, V. J. Interação simulada: Um estudo da transposição da sala de aula para o ambiente virtual. A interação na aprendizagem das línguas. Disponível em http://www.leffa.pro.br/textos/trabalhos/simulada.pdf. Acesso em: março de 2012, v. 1, p. 175-212, 2006.

LIBÂNEO, J. C. Reflexividade e formação de professores: outra oscilação do pensamento pedagógico brasileiro. In: Professor reflexivo no brasil: gênese e crítica de um conceito / PIMENTA, S. G.; GHEDIN, E. (orgs). - 4a ed., São Paulo: Cortez, 2006.

MORIN, E. As cegueiras do conhecimento: o erro e a ilusão. Os Sete saberes necessários à educação do futuro, São Paulo: Cortez; Brasília, DF: UNESCO, 2005.

PAIVA, V. A formação do professor de línguas estrangeiras. Trabalho apresentado no dia 29 de novembro de 1996, durante o I Encontro Nacional sobre Política de Ensino de Línguas Estrangeiras de 1996, promovido pela ALAB em Santa Catarina, no período de 28 a 30 de novembro de 1996. Disponível em http://www.veramenezes.com/formacao.htm. Acesso em: 08 de out. de 2016, p. 9-17, 1996.

ROCHA, N. A.; GILENO, R. S. e. h. A. e. . da S. La práctica pedagógica de un profesor de portugués lengua extranjera (ple) en contexto de inmersión y no-inmersión. Revista IberoAmericana de Estudos em Educação. v.11, n. esp. 1 (2016) Dossiê: X Encontro IberoAmericanodeEducação,v.11,n.25,2016. 
SCHÖN, D. A. Educando o profissional reflexivo: um novo design para o ensino e a aprendizagem. Tradução Roberto Cataldo Costa. [S.1.]: Porto Alegre: Artmed, 2000.

SHULMAN, L. Knowledge and teaching: Foundations of the new reform. Harvard educational review, Harvard Education Publishing Group, v. 57, n. 1, 1987, p. 1-23.

TARDIF, M. Os professores diante do saber: esboço de uma problemática do saber docente. In: Saberes docentes e formação profissional. [S.1.] São Paulo: Vozes, 2002.

VIEIRA-ABRAHÃO, M. H. A formação do professor de línguas de uma perspectiva sociocultural. Signum. Estudos de Linguagem, 2012, p. 457-480.

ZEICHNER, K. M. Uma análise crítica sobre a reflexão como conceito estruturante na formação docente. Educação \& Sociedade. Campinas, vol. 29, n. 103, p. 535-554, maio/ago. 2008. Disponível em http://www.cedes.unicamp.br. Acesso em: 16 de jul. de 2014, v. 29, n. 103, 2008. 